\title{
CALCULATION PROGRAM FOR THE PROCESSING OF LOW- CONCENTRATED TRITIUM AND DEUTERIUM WASTE THROUGH THE CECE ISOTOPIC SEPARATION PROCESS
}

\author{
Anisia Mihaela Bornea*, Marius Valentin Zamfirache \\ National Research and Development Institute for Cryogenics and Isotopic Technologies - ICSI Rm. \\ Valcea, 4 Uzinei Street, P.O. Box Râureni 7, 240050, Rm. Valcea, Romania
}

\begin{abstract}
:
Within the research conducted at our Institute of Cryogenic and Isotopic Technologies (ICSI), is developed a project entitled "Innovative CECE process solution to promote a new technology for decontamination of liquid waste, tritium low concentrated and deuterium recovery".

The main objective of the project carried out within our team is to promote an innovative solution of CECE isotopic separation process (Combined Electrolysis and Catalytic Exchange), part of a new technology for decontamination of liquid waste, poorly concentrated in tritium, generated by nuclear reactors, ensuring increased recovery of the isotope deuterium and tritium.

This paper presents the current stage of an innovative CECE isotopic separation process solution, and also the mathematical model developed for the simulation of hydrogen isotope separation processes through the CECE process and a theoretical analysis based on numerical data resulting from the simulation of two CECE plant operating mode.
\end{abstract}

\section{Article info:}

Received 16 September 2021

Received in revised form 6 October

2021

Accepted 11 October 2021

Available online 9 November 2021

Keywords:

Detritiation, heavy water, waste

management

How to cite: Bornea, A. M., Zamfirache, M. V., (2021). Calculation program for the processing of lowconcentrated tritium and deuterium waste through the CECE isotopic separation process. Smart Energy and Sustainable Environment, 24(2), 97-107, https://doi.org/10.46390/j.smensuen.24221.442

\section{INTRODUCTION}

Within the research objective "Transforming Tritium from a waste into fuel extensive research of isotopic separation and interaction of tritium with matter" is developed the project entitled "Innovative CECE process solution to promote a new technology for decontamination of liquid waste, tritium low concentrated and deuterium recovery".

The main objective of the project is to promote an innovative solution of CECE isotopic separation process, part of a new technology for decontamination of liquid waste 
(Bornea et al., 2018), poorly concentrated in tritium, generated by nuclear reactors, ensuring increased recovery of the isotope deuterium and tritium.

The liquid waste detritiation plant, based on the new detritiation technology, including an innovative CECE isotopic separation process solution, has flexibility in operation, allowing use in several modes of operation, ensuring the achievement of various proposed purposes:

- Waste detritiation of low concentrated HTO tritiated water, in order to increase the degree of tritium recovery, a product that can be used in particular for the commissioning of fusion reactors, as fuel;

- Tritiated heavy water (DTO) detritiation, with low concentrations of deuterium and tritium, having two products - tritium used mainly for fusion reactors, extracted in gaseous form and heavy water that is reintroduced into the fission reactor circuits;

- Heavy water reconcentration by expanding the range of heavy water recovered (less than $1 \% \mathrm{D}_{2} \mathrm{O}$ ).

This paper presents a mathematical model developed for the simulation of hydrogen isotope separation processes through the CECE process and a theoretical analysis based on numerical data resulting from the simulation of two CECE plant operating mode.

\section{CURRENT STAGE OF THE EXPERIMENTAL ISOTOPIC SEPARATION INSTALLATION}

The proposed technology consists of an innovative CECE isotopic separation process solution. Isotope separation by electrolysis is performed with a PEM electrolyzer (Proton Exchange Membrane), reconfigured for the nuclear field of processing tritiated water, including a control software operation; the catalytic isotopic exchange takes place on a mixed catalytic bed structured type, developed by ICSI, with novelty elements on each of the two components (catalyst and hydrophilic packing) as well as in their arrangement (Bornea et al., 2017).

In order to achieve the mentioned objective, an experimental installation of catalytic isotopic exchange - electrolysis (CECE) type was designed and built, and was placed within the PESTD OB 301 (experimental pilot plant for tritium and deuterium separation). The experimental installation (module M1100) has connections with PESTD technological and utility systems.

The electrolyzer existing within PESTD and which is located in a ventilated enclosure (caisson) was integrated within the M1100 module. In order to use the electrolyzer with tritiated fluids and to meet the requirements of interfacing with the equipment within M1100, it was reconfigured in accordance with the current requirements of CNCAN and ISCIR (the two regulatory bodies in the nuclear field and pressurized installations), including modification of instrumentation and control for interconnection with the M1100 main control system.

The installation main components according to the attached simplified scheme in figure 1: Catalytic Isotopic Exchange Column (C-1101), Stripping Column (C-1102), Electrolyzer (EL-1101). Oxygen phase separator vessel (TK-1101), Vessels tanks for product, waste, demineralized water (TK), Catalytic microreactor (MR-1101), Catalytic reactor (RC-1101), Water purifiers (PA), Auxiliary equipment - metering and centrifugal pumps (P), electric heaters (HTR), mechanical filters (STR), chiller (HX), condenser (CD).

Most equipment is manufactured from austenitic stainless steel 304L/316L. 


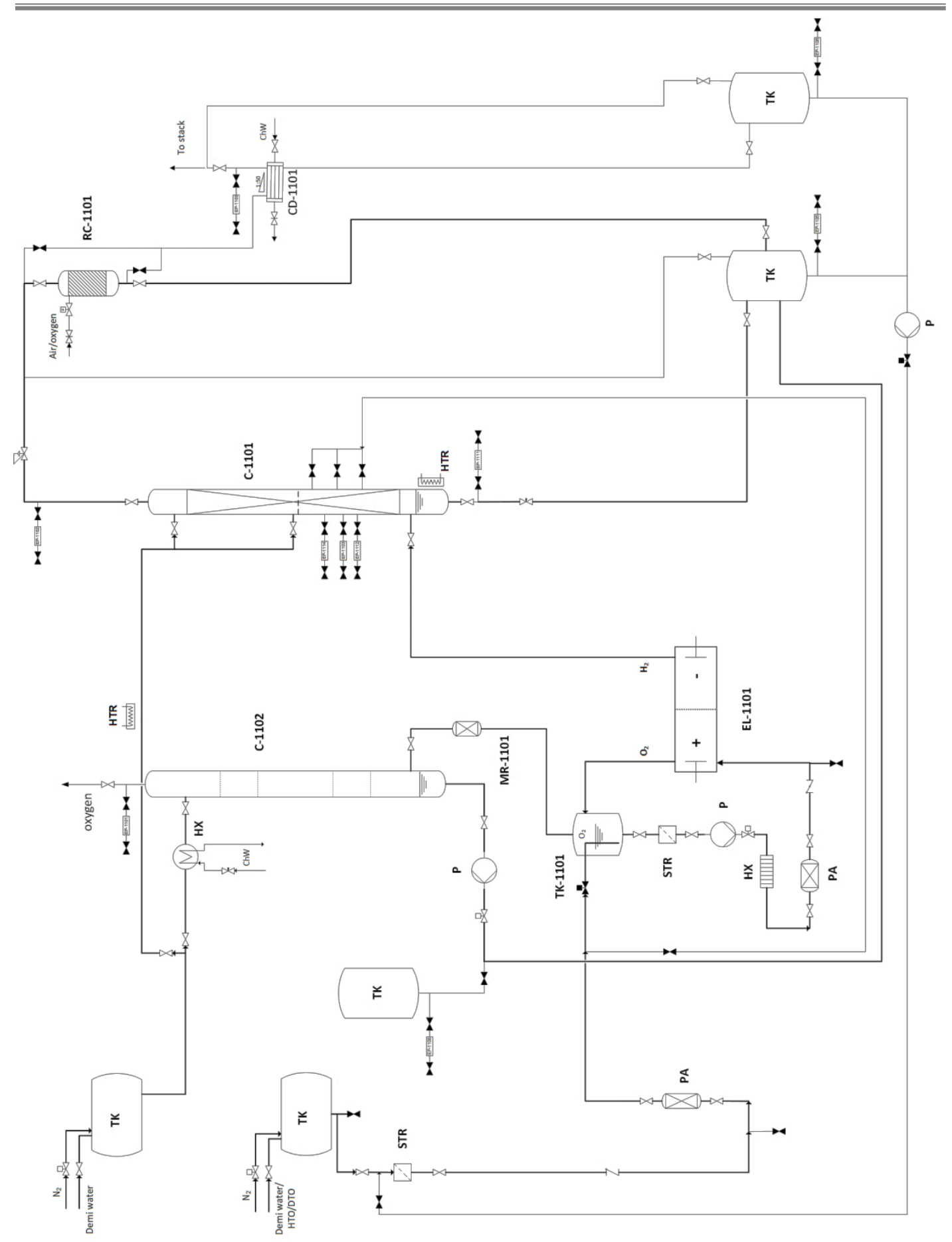

Figure 1. CECE experimental installation scheme

To ensure all the necessary conditions for the experiments, interfaces are provided for: demineralized water, nitrogen gas, instrumental air, deuterated water/tritiated water, chilled/cooling water, electricity, gas discharge to the PESTD stack, connections to process modules within PESTD.

Particular attention was also paid to automation and control activities. An advanced PLC-based control system has been developed to provide reliable information to the 
operator, efficient automatic and manual actions to lead to more efficient control of the plant and to increase its operational safety in terms of hydrogen explosion hazards. and emissions of radioactive materials.

\section{MATHEMATICAL MODEL}

In order to carry out experimental research that will lead to the final goal - promoting the technology of concentrating low tritium and deuterium concentration waste, an analysis tool was developed - a complex calculation program for simulating the CECE isotopic separation process in a non-steady state regime (Bornea et al., 2020).

Industrialized processes for isotope separation of tritiated/deuterated water are mainly equilibrium processes, such as isotopic exchange or distillation, carried out in columns by contacting the liquid phase with the gaseous phase, phases that flow counter-currently and at the interface of which the isotope transfer takes place.

For such processes the mathematical model will aim to describe how the isotope transfer takes place in columns, on contact elements on which equilibrium tends to be obtained, as well as how this process is multiplied in order to separate the desired tritium/deuterium isotope.

This description is commonly made either by admitting that the process of separation into columns proceeds continuously, on homogeneous elements, or discreetly on discontinuous elements. Both methods will be presented, the continuous one allowing a more suggestive representation of the phenomenon and the dependence of the operating parameters and the discrete one, with a higher degree of generality. Practically both methods describe the isotopic concentrations profile along the column, of the fluid circulation and thus of the number of equilibria that are necessary to achieve the desired separation.

The mathematical model developed for the isotopic transfer representation within the CECE isotopic separation process, contains equations for the description of the isotopic transfer separately for the two processes: isotopic separation by electrolysis of tritiated/deuterated water; isotopic separation by catalytic isotopic exchange within the LPCE column equipped with mixed catalytic package, between hydrogen obtained from electrolysis of tritiated/deuterated water and demineralized water flowing counter-currently with gas the representation being made optionally by continuous column method or discrete elements.

The mathematical model is developed to represent the non-steady-state isotopic separation regime.

For the following chapters we will use the notations:

$x$ - liquid concentration

$y$ - gas concentration

$v$-vapor concentration

$H_{L}$ - liquid hold-up

$H_{G}$ - gas hold-up

$H_{V}$ - vapor hold-up

$z$ - height along the column (packed section)

\subsection{CECE - continuous column method}

The representation of the separation process by catalytic isotopic exchange is according to the calculation scheme in figure 2 for the continuous column method.

The continuous column is generally a column equipped with a homogeneous packing (Ionita et al., 2018) that provides a continuous space for isotopic separation. It is used for both distillation and catalytic isotopic exchange. 
The catalytic isotopic exchange is represented by a model with three fluids, liquid-L, vapor-V and gas-G.
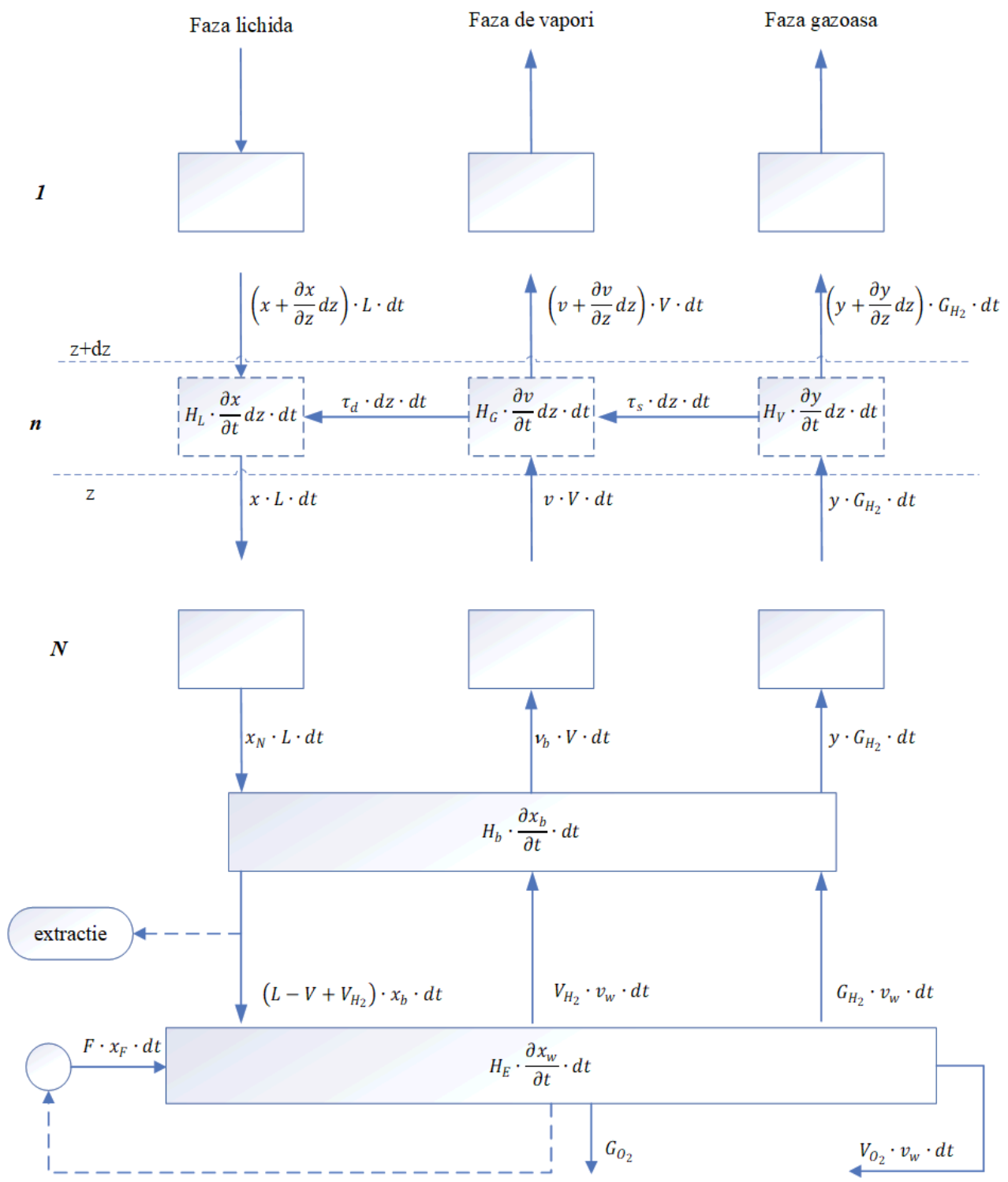

Figure 2. Continuous column method calculation scheme.

The continuous column is generally a column equipped with a homogeneous packing that provides a continuous space for isotopic separation. It is used for both distillation and catalytic isotopic exchange.

The catalytic isotopic exchange is represented by a model with three fluids, liquid-L, vapor-V and gas-G.

For tritium, the transfer takes place simultaneously, after the reactions:

$$
\begin{aligned}
& (\mathrm{HT})_{G}+\left(\mathrm{H}_{2} \mathrm{O}\right)_{V} \rightarrow\left(\mathrm{H}_{2}\right)_{G}+(\mathrm{HTO})_{V} \quad \text { catalytic isotopic exchange } \\
& (\mathrm{HTO})_{V}+\left(\mathrm{H}_{2} \mathrm{O}\right)_{L} \rightarrow\left(\mathrm{H}_{2} \mathrm{O}\right)_{V}+(\mathrm{HTO})_{L} \quad \text { distillation }
\end{aligned}
$$


For the transfer of deuterium from low concentrated water in gas, the following reactions are considered:

$$
\begin{aligned}
& (\mathrm{HD})_{G}+\left(\mathrm{H}_{2} \mathrm{O}\right)_{V} \rightarrow\left(\mathrm{H}_{2}\right)_{G}+(\mathrm{HDO})_{V} \quad \text { catalytic isotopic exchange } \\
& (\mathrm{HDO})_{V}+\left(\mathrm{H}_{2} \mathrm{O}\right)_{L} \rightarrow\left(\mathrm{H}_{2} \mathrm{O}\right)_{V}+(\mathrm{HDO})_{L} \quad \text { distillation }
\end{aligned}
$$

\subsection{CECE - discrete elements method}

It is assumed that the overall chemical exchange is limited by the reaction rate at the catalyst surface or by the transport of the reactants in the catalyst pores. Thus, throughout the column, the vapor mole fraction $v_{i}$ is close to liquid mole fraction $x_{i}$ - the separation factor between liquid and vapor being almost 1 . Considering all this, we can assume that the approximation $d v_{I} \cong d x_{i}$ is as reasonable correct as the following expression:

$$
G \frac{d y_{i}}{d h} \cong(L-V) \frac{d x_{i}}{d h}
$$

According to the literature (Busigin et al., 2017), the errors introduced in the calculation as a result of using this approximation are below $5 \%$.

The representation of the separation process by catalytic isotopic exchange is according to the calculation scheme in figure 3 . for the method with discrete elements, the simplified expression (3.5) being used as basis for the model.

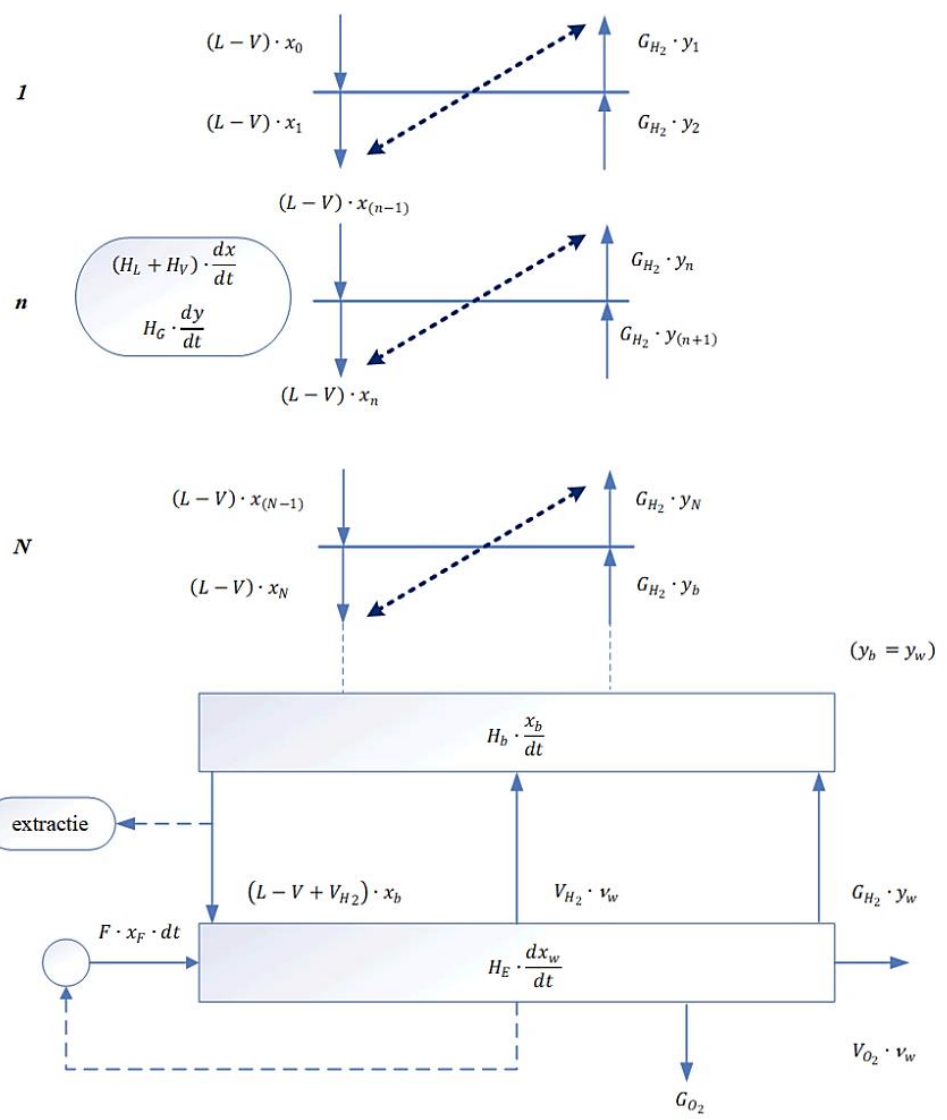

Figure 3. Discrete element method calculation scheme. 
The discrete element in the column is either a plate, on which the two fluids, the liquid and the gas are brought into a stronger contact and through the exchange of mass and energy they are balanced, or a packing volume, on which the two fluids are balances from isotopic and energetic point of view.

The element is characterized by a double input, where the two concentrations in the liquid phase and in the gaseous phase are balanced for the output condition, checking the equilibrium equation. The column method with discrete elements is the method called from plate to plate, which is a mathematical iteration, which is based on solving a system, carried out using a balance relationship.

Solving the equations is done numerically from plate to plate using the calculation program developed, in a first stage in Pascal language, using Embarcadero Rad Studio XE4.

\section{TRITIUM TRANSFER SIMULATION}

The calculation software was used to simulate the tritium transfer within the CECE process in two ways: with the extraction of water from the bottom of the column and in a closed circuit.

The data used to simulate the CECE isotope separation process, in order to perform a first analysis on the data provided by the developed calculation program are:

- LPCE column diameter: $0.04922 \mathrm{~m}$;

- Active height: $5 \mathrm{~m}$;

- Number of Theoretical Plates (NTP)/Height Equivalent to a Theoretical Plate (HETP): 18/0.277m;

- Mass transfer constant (isotopic exchange $s$; distillation $d$ ): $\mathrm{ks}=371 \mathrm{kmol} / \mathrm{m}^{3} \mathrm{~h}, \mathrm{kd}=$ $144 \mathrm{kmol} / \mathrm{m}^{3} \mathrm{~h}$ (Bornea et al., 2019);

- Plate liquid phase hold-up: $4.316315 \mathrm{~mol}$;

- Plate gas phase hold-up: $0.0231264 \mathrm{~mol}$;

- Hold-up in the bottom of the LPCE column: $1 \mathrm{~kg}$;

- Hold-up within electrolyzer: $13 \mathrm{~kg}$;

- Demineralized water supply at the top of the LPCE column: $1.45 \mathrm{~kg} / \mathrm{h}$;

- Hydrogen gas flow generated by electrolysis: $1.90 \mathrm{Nm}^{3} / \mathrm{h}$;

- LPCE column average process temperature: $60^{\circ} \mathrm{C}$;

- Water electrolysis process temperature: $47^{\circ} \mathrm{C}$;

- LPCE column pressure: $120 \mathrm{kPa}$;

- Maximum hydrogen pressure generated by the electrolyzer: $1400 \mathrm{kPa}$;

- The pressure of the Oxygen stream generated by the electrolyzer: $106 \mathrm{kPa}$;

- Tritium isotopic concentration in the demineralized water feed stream at the top of the LPCE column: $2 \mathrm{~Bq} / \mathrm{kg}$;

- Isotopic concentration in the electrolyzer tritiated water supply: $1000 \mathrm{~Bq} / \mathrm{kg}$;

- Tritium separation factor within water electrolysis process: 5.24.

The results are provided by the modelling software in data files (.dat type). For an easier view of the results provided by the software, the data are presented in graphical form. The results obtained with the two calculation models are compared when reaching the steady state regime.

Figure 4 shows the profiles on the gaseous and liquid phase along the catalytic isotopic exchange column, at steady-state, for the operation mode with water extraction at the bottom of the column, determined by the two calculation modes. 


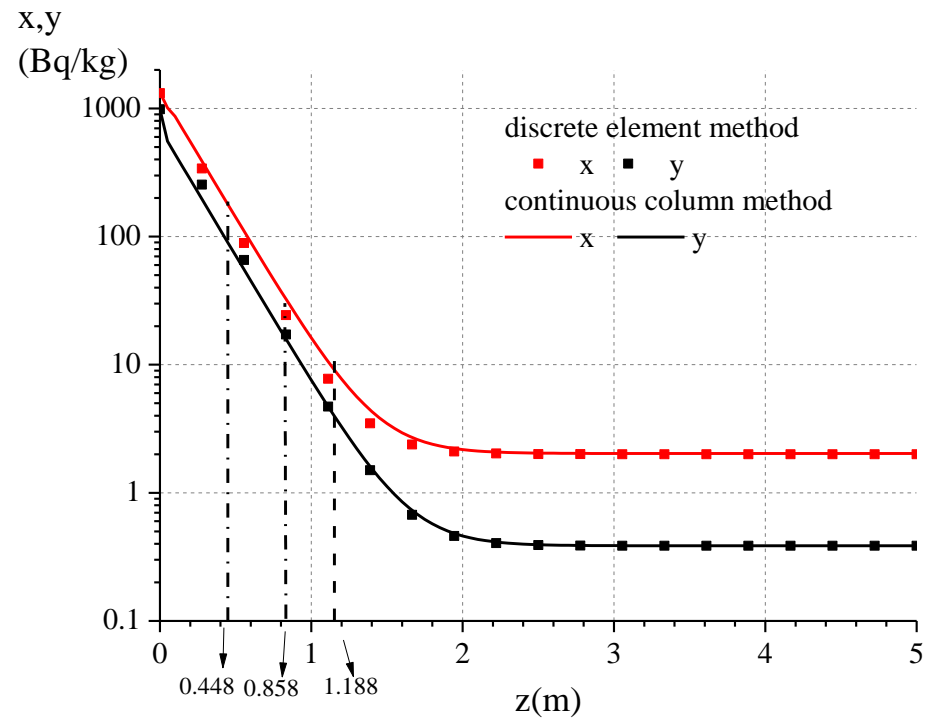

Figure 4. Variation of isotopic concentrations in the liquid and gaseous phase along the LPCE column, steady-state regime, $\mathrm{t}=300$ hours - operation mode with water extraction from the column reboiler.

The figure also shows the concentrations corresponding to the three sampling points on the LPCE column lower section located at $448 \mathrm{~mm}, 858 \mathrm{~mm}$ and $1188 \mathrm{~mm}$ respectively from the base of the column.

There are differences between the two calculation modes. Therefore, it can be considered that the Discrete Element method can be used for a first evaluation of the separation process, but for a rigorous representation it is recommended to use the second mode, Continuous column method.

Figures 5 and 6 graphically represent the variation with time of the isotopic concentrations in the liquid phase in the electrolyzer $\left(\mathrm{x}_{\mathrm{w}}\right)$ and in the LPCE column bottom $\left(\mathrm{x}_{\mathrm{b}}\right)$, for the two modes.

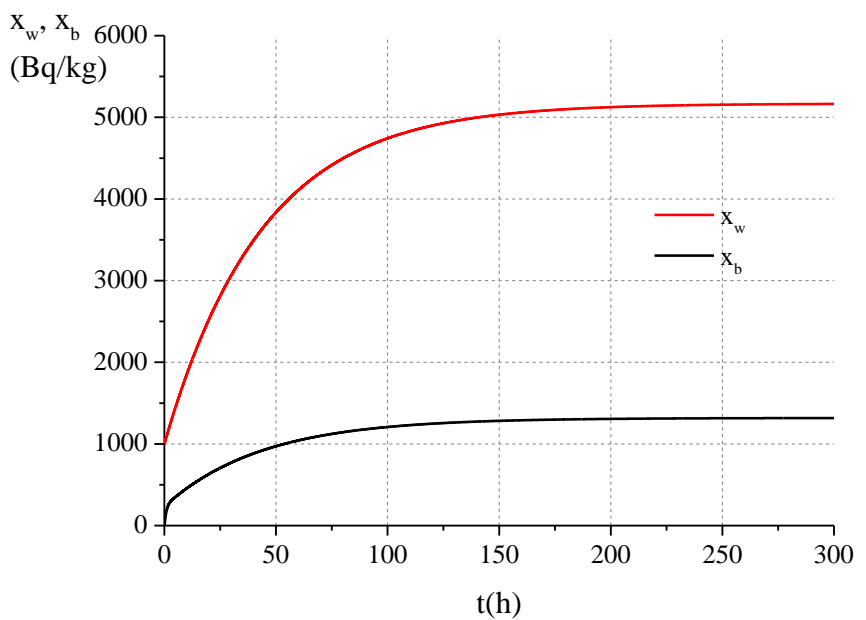

Figure 5. Variation with time of isotopic concentrations in the liquid phase in the electrolyzer $\left(\mathrm{x}_{\mathrm{w}}\right)$ and in the bottom of the LPCE column $\left(\mathrm{x}_{\mathrm{b}}\right)$ - operation mode with the extraction of water from the the column reboiler. 


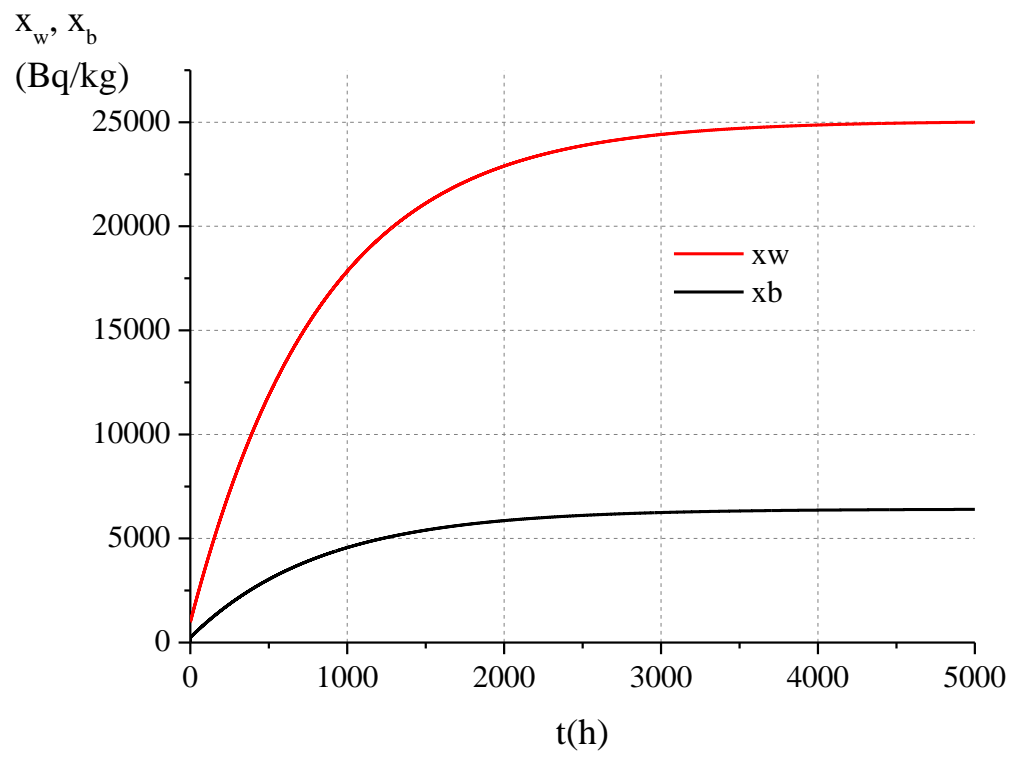

Figure 6. Variation with time of isotopic concentrations in the liquid phase in the electrolyzer $\left(\mathrm{x}_{\mathrm{w}}\right)$ and in the bottom of the LPCE column $\left(\mathrm{x}_{\mathrm{b}}\right)$ - close loop operation mode.

Figure 7 and 8 graphically represent the variation with time of the isotopic concentrations in the liquid phase at the outlet on plate $\mathrm{N}\left(\mathrm{x}_{\mathrm{N}}\right)$ and in the gas phase at the inlet on plate $\mathrm{N}\left(\mathrm{y}_{\mathrm{N}+1}\right)$, for the two modes.

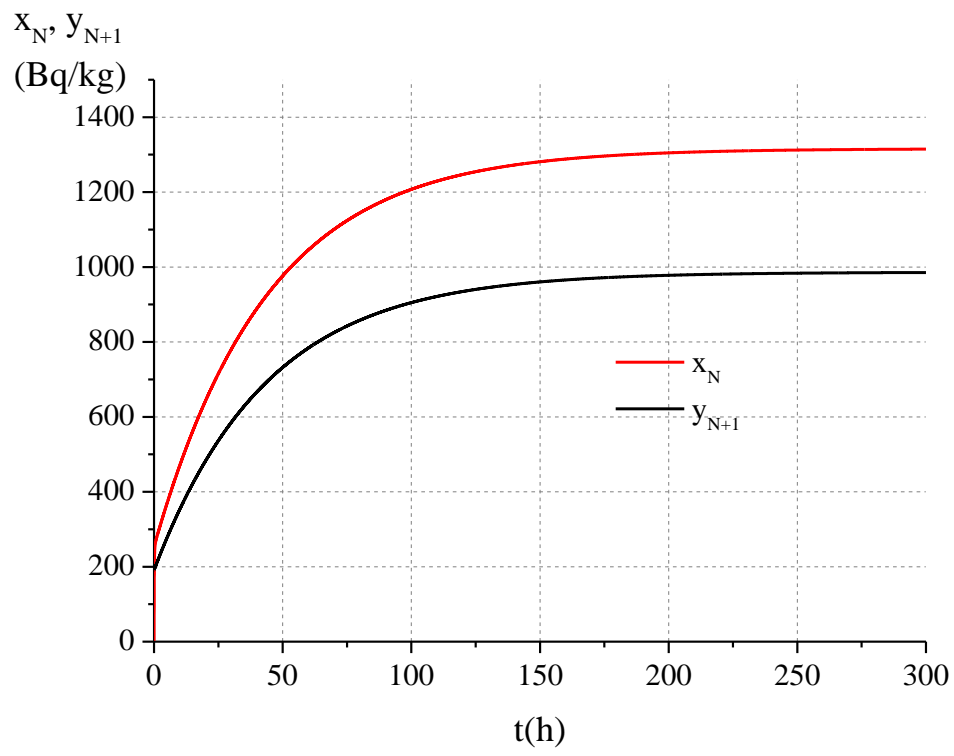

Figure 7. Variation of isotopic concentrations in the liquid phase at the outlet on plate $\mathrm{N}\left(\mathrm{x}_{\mathrm{N}}\right)$ and in the gaseous phase at the inlet on plate $\mathrm{N}\left(\mathrm{y}_{\mathrm{N}+1}\right)$ (corresponds to the hydrogen supplied by the electrolyzer) - operation mode with water extraction from the column reboiler. 


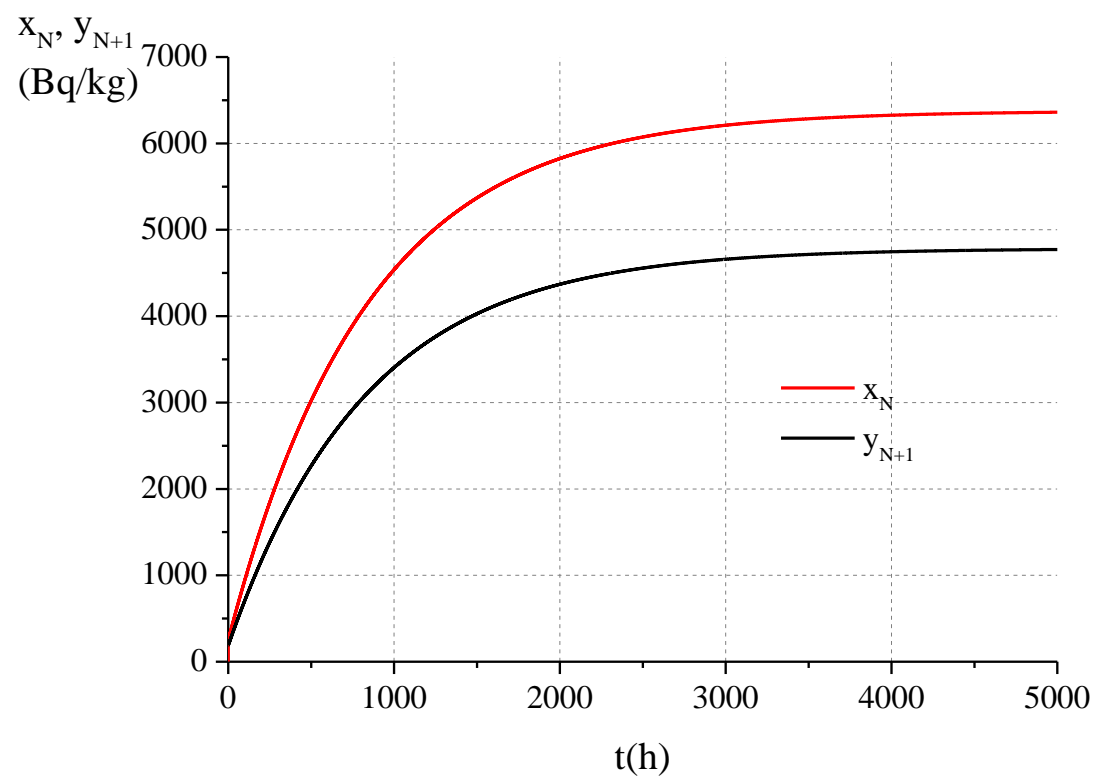

Figure 8. Variation of isotopic concentrations in the liquid phase at the outlet on plate $\mathrm{N}\left(\mathrm{x}_{\mathrm{N}}\right)$ and in the gaseous phase at the inlet on plate $\mathrm{N}\left(\mathrm{y}_{\mathrm{N}+1}\right)$ (corresponds to the hydrogen supplied by the electrolyzer) - close loop operation mode.

The numerical results obtained allow the tracing of the concentration profiles in the liquid and gaseous phase along the LPCE column, at different moment of time until reaching the steady state.

For each analyzed case, it is verified whether the value of the tritium concentration in the gas discharged to the stack exceeds the reference limits $(100 \mathrm{~Bq} / \mathrm{kg}$ desired, respectively $3000 \mathrm{~Bq} / \mathrm{Nm}^{3}$ for maximum allowed).

\section{CONCLUSIONS}

The calculation program for the processing of low-concentrated tritium and deuterium waste through the CECE isotopic separation process was developed.

The simulation provided an image of the variation of isotopic concentrations in nonstationary regime within the CECE separation process - isotopic concentrations on liquid and gaseous phase along the LPCE column, isotopic concentration from the water inside the electrolyzer device and in the LPCE column and isotopic concentration of the generated hydrogen gas.

Two calculation modes for the non-stationary CECE process were presented, indicating the second variant for a rigorous representation of the isotopic separation process.

The simulation provided an image of the variation of isotopic concentrations in a nonstationary regime CECE separation process - isotopic concentrations on liquid and gaseous phase along the LPCE column, isotopic concentration in the water within the electrolyzer and in the bottom of the LPCE column and isotopic concentration of hydrogen gas generated from the electrolyzer.

The numerical data provided by the program show important information on: knowledge of the field of experimentation, in order to limit the release of tritium to the stack, according to regulatory body (CNCAN) norms; concentration of tritium in the liquid phase, by isotopic transfer from the gas phase (hydrogen obtained by electrolysis of 
tritiated water) in the liquid phase, by catalytic isotopic exchange; determining the time to reach the steady-state operating regime.

During the next phase of our research program, a correlation of the data provided by the calculation code developed with the experimental data will be made, in the light water detritiation operation mode, to verify the calculation model and to ensure a high accuracy of the CECE isotopic separation process.

\section{Highlights:}

- According to the strategy and energy policy of Romania, nuclear power has an important role in satisfying the electricity demand.

- During Nuclear Power Plant operation, tritium/deuterium low-concentration water waste are generated.

- This paper may be useful for future tritium/deuterium low-concentration water waste recovery strategies.

Acknowledgements: The work was supported by the Romanian Ministry of Research, Innovation and Digitization - grants number: PN 19110104 "Innovative CECE process solution to promote a new technology for decontamination of liquid waste, tritium low concentrated and deuterium recovery"

Funding: Project PN 19110104, Contract no. 119104/1191, financed by the Romanian Ministry of Research, Innovation and Digitization, Romania.

Author contributions: A.M.B., M.V.Z. wrote the original draft, and all authors contributed to the analysis and article review. A.M.B. coordinated the analysis for this paper. Figures were created by M.V.Z. and A.M.B. All authors have formulated the conclusions.

Conflict of Interest Statement: The authors declare no conflicts of interest associated with this manuscript.

\section{REFERENCES}

Bornea A., Zamfirache M., Bidica N., 2018. Proposal for Combined Electrolysis and Catalytic Exchange System (CECE) Development Within the Pilot Plant. Fusion Eng. Des., 136, 645 (2018). https://doi.org/10.1016/j.fusengdes.2018.03.046.

Bornea A. et al., 2017. Theoretical Analysis for Setting up a Ctalyst-Packing Mixture that Equips a Ctalytic Isotopic Exchange Column. Fusion Sci. Technol., 71, 4, 532 (2017). https://doi.org/10.1080/15361055.2017.1290973

Bornea A. et al., 2020. The Study of CECE Process for Low-Tritiated Liquid Waste Prior to Experimental Phase. Fusion Sci. Technol., 76, 4, 384-391. https://doi.org/10.1080/15361055.2020.1712991.

Bornea A. et al., 2018. New catalytic packing performance: Theoretical and experimental characterization for LPCE process. Fusion Eng. Des., 146, 2384 (2018). https://doi.org/10.1016/j.fusengdes. 2019.03.196.

Busigin A., 2017. Rigorous Two-Fluid and Three-Fluid Phase Catalytic Exchange Models and Their Application. Fusion Sci. Technol., 71, 438-443. https://dx.doi.org/10.1080/15361055.2017.1293411.

Ionita G., Spiridon I., Bucur C., 2018. Hydrodinamic Characteristics of Mixed Catalytic Packing for Heavy Water Detritiation. Fusion Eng. Des., 136, 1252 (2018). https://doi.org/10.1016/j.fusengdes. 2018.03.111. 